\title{
ASPECTS OF THE CALCULATION OF CORRELATIONS ON THE BUCHAREST STOCK EXCHANGE
}

\author{
Teodor Hada ${ }^{l}$ \\ Halga (Corpodean) Dana ${ }^{2}$
}

\begin{abstract}
In the present study we aimed to determine correlations between the profit of the firms and the value of their shares for 2010, and between the Down Jones index and the share prices on the stock market. The study is structured in two parts: in the first part, we establish correlations between the share price and profit, and between Down Jones indicator, and the course of the share prices based on econometric models. In the second part of the present study, we used the SPSS program, and we calculate the same correlations with this program.

We made use of the following types of research: descriptive research, explanatory research, and applied research.

The novelty of the study is determined by the fact that we employed econometric methods and the SPSS (Statistical Package for the Social Sciences) program to establish correlations between different variables.
\end{abstract}

Key words: correlations, stock market, statistical observation

JEL codes: $G 24$

\section{Introduction}

By the financial investments, the investors on the capital market expect a yield which is the average yield plus a risk premium for the investment in this field. The yield depends on the dividends expected by the investors and on the differences of the exchange rates, by the formula:

$$
\eta_{1}=\frac{D_{1}}{C_{0}}+\frac{C_{1}-C_{0}}{C_{0}}(1)
$$

where $\mathrm{C}_{0}$ - price of acquisition

$\mathrm{C}_{1}=$ price of resale

$\mathrm{D}_{1}=$ expected dividend

For obtaining dividends the investors follow two indicators, namely:

- the rate of distributing dividends (d), which shows how much of the net benefit is distributed for paying dividends, and is calculated by using the following formula:

$\mathrm{d}=$ Net dividends/Net benefit $\mathrm{x} 100$ (2)

- per share benefit, which shows how much current benefit returns on a share for the investor, and is is calculated by using the following formula:

Per share benefit $=$ Current benefit/Number of shares (3)

\section{Correlations between the profit index and the value of shares on BSE in 2010}

In this study, we performed a statistical observation of the 25 companies that have shares listed on Bucharest Stock exchange, and are part of the first category, taking into account the value

\footnotetext{
1 “1 Decembrie 1918” University, Alba Iulia, Romania, e-mail: teohada@yahoo.com

2 “Dionisie Pop Martian” Economic College, Romania, Alba Iulia, e-mail: danahalga@yahoo.com
} 
of the action and profit in the end of 2010. The source of these statistical data is the site of BSE: www.bvb.ro.

Statistical observations was made in relation to the share price transactions $(\mathrm{X})$ and profit (Y). The statistical observation resulted in the following table (http://www.bvb.ro/Companies/qshares.aspx? $\mathrm{m}=\mathrm{bse} \& \mathrm{t}=0$ ):

Table no. 1.

The value of shares and the profit at the end of 2010 of the 25 companies listed on Bucharest Stock Exchange

\begin{tabular}{|r|r|r|}
\hline \multicolumn{1}{|c|}{ No. } & X-value & \multicolumn{1}{c|}{ Y-profit } \\
\hline 1 & 2.99 & $159,781,849.00$ \\
\hline 2 & 0.44 & $12,539,100.00$ \\
\hline 3 & 0.48 & $153,958,847.00$ \\
\hline 4 & 0.21 & $14,414,793.00$ \\
\hline 5 & 12.35 & $500,589,835.00$ \\
\hline 6 & 0.29 & $6,651,811.00$ \\
\hline 7 & 0.14 & $3,527,197.00$ \\
\hline 8 & 0.47 & $2,008,441.00$ \\
\hline 9 & 0.20 & $3,362,632.00$ \\
\hline 10 & 1.90 & $10,881,737.00$ \\
\hline 11 & 1.10 & $9,557,424.00$ \\
\hline 12 & 19.35 & $1,799,154,602.00$ \\
\hline 13 & 0.34 & $376,352,986.00$ \\
\hline 14 & 28.00 & $62,996,316.00$ \\
\hline 15 & 1.01 & $96,293,949.00$ \\
\hline 16 & 1.16 & $71,419,776.00$ \\
\hline 17 & 0.64 & $80,994,938.00$ \\
\hline 18 & 1.26 & $66,919,410.00$ \\
\hline 19 & 0.54 & $4,462,356.00$ \\
\hline 20 & 0.37 & $97,493,089.00$ \\
\hline 21 & 0.09 & $11,276,413.00$ \\
\hline 22 & 1.01 & $2,948,021.00$ \\
\hline 23 & 0.04 & $2,173,848.00$ \\
\hline 24 & 1.45 & $435,115.00$ \\
\hline 25 & 0.79 & $1,944,272.00$ \\
\hline
\end{tabular}

In order to verify the correlation between the two variables, we used the econometric model that functions on the basis of the following formula:

$$
\mathrm{r}=\frac{\mathrm{N} * \sum \mathrm{X}^{*} \mathrm{Y}-\sum \mathrm{X} * \sum \mathrm{Y}}{\sqrt{\mathrm{N} * \sum \mathrm{X}^{2}-\left(\sum \mathrm{X}\right)^{2}} * \sqrt{\mathrm{N} * \sum \mathrm{Y}^{2}-\left(\sum \mathrm{Y}\right)^{2}}}
$$

where r- correlation report

$\mathrm{N}$ - number of subjects

Table no. 2.

The calculation of the correlation indicators

\begin{tabular}{|r|r|r|r|r|r|}
\hline \multicolumn{1}{|l|}{ No. } & X-value & \multicolumn{1}{c|}{ Y-profit } & \multicolumn{1}{c|}{$\mathbf{X}^{\mathbf{2}}$} & \multicolumn{1}{c|}{$\mathbf{Y}^{\mathbf{2}}$} & \multicolumn{1}{c|}{$\mathbf{X}^{* \mathbf{Y}}$} \\
\hline 1 & 2.99 & $159,781,849.00$ & 8.9401 & 255.30 & 47.77 \\
\hline 2 & 0.44 & $12,539,100.00$ & 0.19018321 & 1.57 & 0.55 \\
\hline
\end{tabular}




\begin{tabular}{|r|r|r|r|r|r|}
\hline 3 & 0.48 & $153,958,847.00$ & 0.2304 & 237.03 & 7.39 \\
\hline 4 & 0.21 & $14,414,793.00$ & 0.042025 & 2.08 & 0.30 \\
\hline 5 & 12.35 & $500,589,835.00$ & 152.5225 & 2505.90 & 618.23 \\
\hline 6 & 0.29 & $6,651,811.00$ & 0.0841 & 0.44 & 0.19 \\
\hline 7 & 0.14 & $3,527,197.00$ & 0.0196 & 0.12 & 0.05 \\
\hline 8 & 0.47 & $2,008,441.00$ & 0.22099401 & 0.04 & 0.09 \\
\hline 9 & 0.20 & $3,362,632.00$ & 0.041209 & 0.11 & 0.07 \\
\hline 10 & 1.90 & $10,881,737.00$ & 3.61 & 1.18 & 2.07 \\
\hline 11 & 1.10 & $9,557,424.00$ & 1.21 & 0.91 & 1.05 \\
\hline 12 & 19.35 & $1,799,154,602.00$ & 374.4225 & 32369.57 & 3481.36 \\
\hline 13 & 0.34 & $376,352,986.00$ & 0.112225 & 1416.42 & 12.61 \\
\hline 14 & 28.00 & $62,996,316.00$ & 784 & 39.69 & 176.39 \\
\hline 15 & 1.01 & $96,293,949.00$ & 1.028196 & 92.73 & 9.76 \\
\hline 16 & 1.16 & $71,419,776.00$ & 1.350244 & 51.01 & 8.30 \\
\hline 17 & 0.64 & $80,994,938.00$ & 0.414736 & 65.60 & 5.22 \\
\hline 18 & 1.26 & $66,919,410.00$ & 1.5876 & 44.78 & 8.43 \\
\hline 19 & 0.54 & $4,462,356.00$ & 0.29539225 & 0.20 & 0.24 \\
\hline 20 & 0.37 & $97,493,089.00$ & 0.1369 & 95.05 & 3.61 \\
\hline 21 & 0.09 & $11,276,413.00$ & 0.00893025 & 1.27 & 0.11 \\
\hline 22 & 1.01 & $2,948,021.00$ & 1.0201 & 0.09 & 0.30 \\
\hline 23 & 0.04 & $2,173,848.00$ & 0.00164025 & 0.05 & 0.01 \\
\hline 24 & 1.45 & $435,115.00$ & 2.1025 & 0.00 & 0.06 \\
\hline 25 & 0.79 & $1,944,272.00$ & 0.616225 & 0.04 & 0.15 \\
\hline Total & 76.6227 & 3552138757 & 1334.2083 & 37181.19 & 4384.311 \\
\hline
\end{tabular}

As result of data analysis from above, we obtained the correlation between the two variables, i.e. value $r=0.729493$; good correlation, $r \in[-1 ; 1]$.

\section{Bond Intensity Analysis Using Fisher's Test}

On the basis of the observation table, we systematized the observation data seen in the following correlation table:

Table no. 3 .

The frequency of companies based on the value stocks and profit

\begin{tabular}{|c|c|c|c|c|}
\hline $\mathbf{y} / \mathbf{x}$ & {$[\mathbf{0 - 1 0})$} & {$[\mathbf{1 0 - 2 0})$} & {$[\mathbf{2 0 - 3 0})$} & TOTAL \\
\hline$[0-50]$ & 22 & & 1 & $\mathbf{2 3}$ \\
\hline$[50-100)$ & & 1 & & $\mathbf{1}$ \\
\hline$[100-150)$ & & & & $\mathbf{0}$ \\
\hline$[150-200)$ & & 1 & & $\mathbf{1}$ \\
\hline TOTAL & $\mathbf{2 2}$ & $\mathbf{2}$ & $\mathbf{1}$ & $\mathbf{2 5}$ \\
\hline
\end{tabular}

In the table above, we emphasized the correlation between variable $X$-value stocks in 2010 , and variable y 2010 -profit for 2010 (expressed in the correlation table in thousands lei)

1. We formulate the null hypothesis together with the alternative hypothesis:

$H_{0}: r_{01}=0$ (the $\mathrm{X}$ factor is not a significant influence factor for $\mathrm{Y}$, there is no correlation, it is low intensity )

$H_{1}: r_{01} \neq 0$ ( the $\mathrm{X}$ factor is not a significant influence factor for $\mathrm{Y}$, there is correlation, high intensity). 
2. On the basis of the collected data, we calculate the correlation report based on the total variance and the explained variance.

The correlation report is calculated using the formula:

$$
\hat{r}_{01}=\sqrt{\frac{V_{\text {exp }}}{V_{\text {tot }}}}=0.877523026
$$

The total variance is provided by the formula:

$$
V_{\text {tot }}=\sigma_{Y}^{2}=\frac{\sum_{i=1}^{I}\left(y_{i}-\bar{Y}\right)^{2} \cdot n_{i} .}{\sum_{i=1}^{I} n_{i} .}=1632.96(6)
$$

The reckoning of the total variance:

$\overline{\mathrm{Y}}=\frac{\sum_{\mathrm{i}=1}^{\mathrm{I}} \mathrm{y}_{\mathrm{i}} \cdot \mathrm{n}_{\mathrm{i}}}{\sum_{\mathrm{i}=1}^{\mathrm{I}} \mathrm{n}_{\mathrm{i}}}$

$\hat{\bar{Y}}=\frac{5^{*} 22+15^{*} 2+25 * 1}{25}=33$

$\mathrm{V}_{\text {tot }}=\frac{(25-33)^{2} * 23+(75-33)^{2} * 1+(125-33)^{2} * 0+(175-33)^{2} * 1}{25}=936$

$\mathrm{V}_{\text {tot }}=936$

The explained variance is given by the formula:

$\mathrm{V}_{\text {exp }}=\sigma_{\overline{\mathrm{Y}} / \mathrm{x}}^{2}=\frac{\sum_{\mathrm{j}=1}^{\mathrm{J}}\left(\overline{\mathrm{Y}} / \mathrm{x}_{\mathrm{j}}-\overline{\mathrm{Y}}\right)^{2} \cdot \mathrm{n}_{\cdot \mathrm{j}}}{\text { The reckoning of }} \sum_{\mathrm{j}=1}^{\mathrm{J}} \mathrm{n}_{\cdot \mathrm{j}}$ the exp

$$
\begin{aligned}
& \bar{Y} / X_{j}=\frac{\sum_{i=1}^{I} y_{i} \cdot n_{i j}}{\sum_{i=1}^{I} n_{i j}}=736 \\
& \hat{\bar{Y}} / X 11)=25 ; \hat{\bar{Y}} / X 2=125 ; \hat{\bar{Y}} / X 3=25 \\
& \mathrm{~V}_{\exp }=736
\end{aligned}
$$

Reckoning for the correlation report:

$$
\hat{r}_{01}=\sqrt{\frac{V_{\text {exp }}}{V_{\text {tot }}}}=\sqrt{\frac{736}{936}}=0,88675 \in(-1 ; 1)
$$

results a relatively high intensity at the sample level.

3. The statistical test $\mathrm{F}$ is based on the aleatory variance: 


$$
F=\frac{r_{01}^{2} /(J-1)}{\left(1-r_{01}^{2}\right) /(n-J)} \in \mathrm{F}(\mathrm{J}-1, \mathrm{n}-\mathrm{J})
$$

That follows the probability law by Fisher, with $\gamma_{1}=\mathrm{J}-1$ and $\gamma_{2}=\mathrm{n}-\mathrm{J}$, freedom degrees.

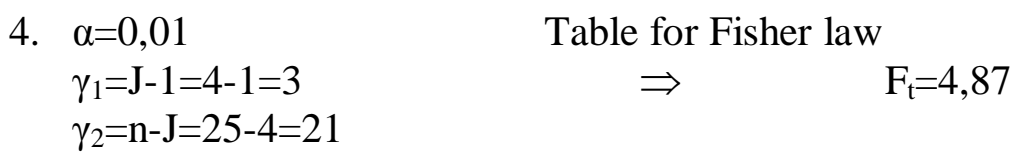

The area of accepting the hypothesis will be $[0 ; 4,87]$

5. We calculate the particular value of the $\mathrm{F}$ variable on the basis of the data obtained with the sample.

$$
\mathrm{F}_{\text {calc }}=\frac{\hat{\mathrm{r}}_{01}^{2} /(\mathrm{J}-1)}{\left(1-\hat{\mathrm{r}}_{01}^{2}\right) /(\mathrm{n}-\mathrm{J})}=\frac{(0.88675)^{2} / 3}{\left(1-(0.88675)^{2}\right) / 21}=25.76(14)
$$

6. The decision taking process

Since 25.76 does not belong to [0, 4.68], we reject the null hypothesis, and accept the alternative hypothesis; therefore $\mathrm{r} 01$ is not 0 , and $\mathrm{X}$ is a significant factor influencing $\mathrm{y}$; the significance threshold is $1 \%$.

Correlations between the Down Jones Indicator and the share prices in the companies listed on BSE in 2010

For this study, we performed a statistical observation on 12 action values recorded at the beginning of each month for the year 2010, for the following companies: ALRO S.A, BRD GROUPE SOCIETE GENERALE S.A. and ALUMIL ROM INDUSTRY S.A. (ALU), and the Down Jones index value recorded for the same period of time. The source of these statistical data is the site of BSE, www.bvb.ro.

The statistical observation was made in relation to the value of the shares $(\mathrm{X})$ and the Down Jones indicator (Y). The statistical observation results can be found in the following table:

Table no. 4.

The correlation between the value of the shares and the Down Jones indicator for the three companies

\begin{tabular}{|l|r|r|r|r|r|r|}
\hline No. & \multicolumn{1}{|l|}{ X-ALU-DJ } & \multicolumn{1}{l|}{ Y-ALRO } & \multicolumn{1}{l|}{ Y-DJ } & \multicolumn{1}{l|}{ X-BRD } & \multicolumn{1}{l|}{ Y-DJ } \\
\hline 1 & 2.26 & 10618.19 & 2.66 & 10618.19 & 14.5 & 10618.19 \\
\hline 2 & 2.35 & 10012.23 & 2.85 & 10012.23 & 14.5 & 10012.23 \\
\hline 3 & 2.56 & 10566.2 & 2.9 & 10566.2 & 14.6 & 10566.2 \\
\hline 4 & 2.84 & 10927.07 & 3.73 & 10927.07 & 15.9 & 10927.07 \\
\hline 5 & 1.68 & 10380.43 & 2.81 & 10380.43 & 13.4 & 10380.43 \\
\hline 6 & 1.46 & 9931.97 & 2.95 & 9931.97 & 12 & 9931.97 \\
\hline 7 & 1.49 & 9686.48 & 2.94 & 9686.48 & 10.8 & 9686.48 \\
\hline 8 & 1.72 & 10653.56 & 3.1 & 10653.56 & 11.8 & 10653.56 \\
\hline 9 & 1.64 & 10447.93 & 2.7 & 10447.93 & 11.5 & 10447.93 \\
\hline 10 & 1.65 & 10829.68 & 3 & 10829.68 & 12.2 & 10829.68 \\
\hline 11 & 1.54 & 11444.08 & 3 & 11444.08 & 12.3 & 11444.08 \\
\hline 12 & 1.54 & 11382.09 & 3.03 & 11382.09 & 12.1 & 11382.09 \\
\hline Total & 22.73 & 126879.91 & 35.67 & 126879.91 & 155.6 & 126879.91 \\
\hline
\end{tabular}

a) ALRO S.A.

The correlation obtained with the above mentioned formula has the following value: $r=$ 0.322948

Bond intensity analysis of correlation using the Fisher test 
We systematized the observed data on the basis of the observation table, in another observation table:

Table no. 5 .

The frequency of the companies based on the value stocks and Down Jones index

\begin{tabular}{|c|c|c|c|c|}
\hline $\mathbf{y}-\mathbf{x}$ & {$[\mathbf{0 - 5})$} & {$[\mathbf{5 - 1 0}$} & {$[\mathbf{1 0 - 1 5})$} & TOTAL \\
\hline$[0-5]$ & & & & 0 \\
\hline$[5-10)$ & 2 & & & 2 \\
\hline$[10-15)$ & 10 & & & 10 \\
\hline TOTAL & 12 & 0 & 0 & 12 \\
\hline
\end{tabular}

In the table above, we have shown the correlation between the variable $\mathrm{X}$ - value stocks for 2010 and variable Y - the Down Jones index value for 2010 (expressed in the correlation table in thousands of lei). The correlation report is calculated using the following formula:

$\hat{r}_{01}=\sqrt{\frac{V_{\text {exp }}}{V_{\text {tot }}}}=0 €(-1 ; 1) \Rightarrow$ the bond is low, at the sample level (15)

The total variance is provided by the formula:

$$
\begin{aligned}
& \mathrm{V}_{\text {tot }}=\sigma_{\mathrm{Y}}^{2}=\frac{\sum_{\mathrm{i}=1}^{\mathrm{I}}\left(\mathrm{y}_{\mathrm{i}}-\overline{\mathrm{Y}}\right)^{2} \cdot \mathrm{n}_{\mathrm{i} \cdot}}{\sum_{\mathrm{i}=1}^{\mathrm{I}} \mathrm{n}_{\mathrm{i} \cdot}}=3.472222(16) \\
& \hat{\bar{Y}}=\frac{5 * 22+15^{*} 2+25 * 1}{25}=11.66667(17) \\
& V_{\exp }=\sigma_{\bar{Y} / X}^{2}=\frac{\sum_{j=1}^{J}\left(\bar{Y} / x_{j}-\bar{Y}\right)^{2} \cdot n_{\cdot j}}{\sum_{j=1}^{J} n_{\cdot j}}=0(18)
\end{aligned}
$$

$$
\begin{aligned}
& \alpha=0,01 \\
& \begin{array}{l}
\gamma_{1}=\mathrm{J}-1=3-1=2 \\
\gamma_{2}=\mathrm{n}-\mathrm{J}=12-3=9
\end{array}
\end{aligned} \quad \begin{gathered}
\text { The table for Fisher Law } \\
\end{gathered}
$$

The acceptance area of hypothesis will be $[0 ; 8,02]$.

We calculate a particular value for the variable $F$ on the basis of the data obtained using the sample:

$$
F_{\text {calc }}=\frac{\hat{r}_{01}^{2} /(J-1)}{\left(1-\hat{r}_{01}^{2}\right) /(n-J)}=\frac{(0.13484)^{2} / 3}{\left(1-(0.13484)^{2}\right) / 8}=0
$$

The decision taking process

Since 0 belongs to [0;7,59], we accept the null hypothesis and reject the alternative; hence, $r_{01}=0$, and $X$ is not a significant influence factor for $Y$.

b) BRD - GROUPE SOCIETE GENERALE S.A. 
The correlation obtained with the above mentioned formula has the following value: $r=$ 0.140637 .

The bond intensity analysis using the Fisher test

We systematized the observed data from the observation table in the following correlation table:

Table no. 6.

\section{The frequency of the companies based on the share price and the value} of the Down Jones indicator

\begin{tabular}{|c|c|c|c|c|c|}
\hline $\mathbf{y} / \mathbf{x}$ & {$[\mathbf{0 - 5})$} & {$[\mathbf{5 - 1 0})$} & {$[\mathbf{1 0 - 1 5})$} & $\mathbf{1 5 - 2 0}$ & TOTAL \\
\hline$[0-5]$ & & & & & 0 \\
\hline$[5-10)$ & & & 2 & & 2 \\
\hline$[10-15)$ & & & 9 & 1 & 10 \\
\hline$[15-20)$ & & & & & 0 \\
\hline TOTAL & 0 & 0 & 11 & 1 & 12 \\
\hline
\end{tabular}

In the table above, we emphasised the correlation between the variable $\mathrm{X}$ - share price in 2010 and variable Y - value of the Down Jones indicator for 2010 (expressed in the correlation table in thousands of lei).

The correlation report is calculated according to the following formula:

$\hat{r}_{01}=\sqrt{\frac{V_{\text {exp }}}{V_{\text {tot }}}}=0.13484 \in(-1 ; 1)(20) \Rightarrow$ the bond gives a rather law value for intensity, at the sample level.

The total variance is provided by the formula:

$$
\begin{aligned}
& V_{\text {tot }}=\sigma_{Y}^{2}=\frac{\sum_{i=1}^{I}\left(y_{i}-\bar{Y}\right)^{2} \cdot n_{i \cdot}}{\sum_{i=1}^{I} n_{i \cdot}}=3.472222 \\
& \hat{\bar{Y}}=\frac{5 * 22+15^{*} 2+25 * 1}{25}=11.66667 \\
& V_{\exp }=\sigma_{\bar{Y} / x}^{2}=\frac{\sum_{j=1}^{J}\left(\bar{Y} / x_{j}-\bar{Y}\right)^{2} \cdot n_{\cdot j}}{\sum_{j=1}^{J} n_{\cdot j}}=0.063131
\end{aligned}
$$

$$
\alpha=0,01
$$

$\gamma_{1}=\mathrm{J}-1=4-1=3$

$$
\Rightarrow \begin{gathered}
\text { The table of Fisher Law } \\
\mathrm{F}_{\mathrm{t}}=7,59
\end{gathered}
$$$$
\gamma_{2}=\mathrm{n}-\mathrm{J}=25-4=21
$$

The acceptance area for hypothesis will be $[0 ; 7,59]$

We calculate a particular value of the variable $F$ on the basis of the data obtained using the sample.

$$
F_{\text {calc }}=\frac{\hat{r}_{01}^{2} /(J-1)}{\left(1-\hat{r}_{01}^{2}\right) /(n-J)}=\frac{(0.13484)^{2} / 3}{\left(1-(0.13484)^{2}\right) / 8}=0.049383
$$

Decesion taking process 
Since 0.049383 belongs to $[0 ; 7,59]$, we accept the null hypothesis and reject the alternative hypothesis; therefore, $\mathrm{r}_{01}=0$; it means that $\mathrm{x}$ is not a significant influence factor for $\mathrm{y}$.

c) ALUMIL ROM INDUSTRY S.A.

The correlation obtained with the above mentioned formula has the following value: $r=$ 0.045988 .

\section{The bond intensity analysis using the Fisher test}

On the basis of the observation table, we systematized the observed data in the following correlation table, and we realized the fact that the correlative influence and the influence observed in the case of the shares of ALRO S.A have the same value.

Table no. 7.

The frequency of ALRO SA based on the share price and the value of the Down Jones indicator

\begin{tabular}{|c|c|c|c|c|}
\hline $\mathbf{x}$ & {$[0-5)$} & {$[5-10)$} & {$[10-15)$} & TOTAL \\
\hline$[0-5]$ & & & & 0 \\
\hline $\begin{array}{l}5-10) \\
\end{array}$ & 2 & & & 2 \\
\hline$[10-15)$ & 10 & & & 10 \\
\hline TOTAL & 12 & 0 & 0 & 12 \\
\hline
\end{tabular}

\section{Correlations on the basis of SPSS program}

We used the same series of data with the SPSS program, and we obtained the following results (we give the reckoning, the tables resulted plus the interpretation)

Table no. 8 .

\section{Correlations}

\begin{tabular}{|l|l|r|r|}
\hline & & X-valoare & \multicolumn{1}{|c|}{ Y-profit } \\
\hline X-valoare & Pearson Correlation & 1 & $.554^{* * *}$ \\
\cline { 2 - 4 } & Sig. (2-tailed) & & .004 \\
\cline { 2 - 4 } & $\mathrm{N}$ & 25 & 25 \\
\hline Y-profit & Pearson Correlation & $.554^{* *}$ & 1 \\
\cline { 2 - 4 } & Sig. (2-tailed) & .004 & \\
\cline { 2 - 4 } & $\mathrm{N}$ & 25 & 25 \\
\hline
\end{tabular}

**. Correlation is significant at the 0.01 level (2-tailed).

There is a direct correlation between the two variables

Table no. 9.

\section{Correlations}

\begin{tabular}{|l|l|r|r|}
\hline & & \multicolumn{1}{|c|}{ X-BRD } & \multicolumn{1}{|c|}{ Y-DJ } \\
\hline X-BRD & Pearson Correlation & 1 & .141 \\
\cline { 2 - 4 } & Sig. (2-tailed) & & .663 \\
\cline { 2 - 4 } & $\mathrm{N}$ & 12 & 12 \\
\hline \multirow{3}{*}{ Y-DJ } & Pearson Correlation & .141 & 1 \\
\cline { 2 - 4 } & Sig. (2-tailed) & .663 & \\
\cline { 2 - 4 } & $\mathrm{N}$ & 12 & 12 \\
\hline
\end{tabular}

Inexistent correlations

Table no. 10. 


\section{Correlations}

\begin{tabular}{|l|l|r|r|}
\hline & & X-ALRO & \multicolumn{1}{|c|}{ Y-DJ } \\
\hline \multirow{3}{*}{ X-ALRO } & Pearson Correlation & 1 & .323 \\
\cline { 2 - 4 } & Sig. (2-tailed) & & .306 \\
\cline { 2 - 4 } & $\mathrm{N}$ & 12 & 12 \\
\hline \multirow{3}{*}{ Y-DJ } & Pearson Correlation & .323 & 1 \\
\cline { 2 - 4 } & Sig. (2-tailed) & .306 & \\
\cline { 2 - 4 } & $\mathrm{N}$ & 12 & 12 \\
\hline
\end{tabular}

Inexistent correlation

Table no. 11.

\begin{tabular}{|l|l|r|r|}
\hline & & \multicolumn{1}{|c|}{ X-ALU } & \multicolumn{1}{|c|}{ Y-DJ } \\
\hline \multirow{2}{*}{ X-ALU } & Pearson Correlation & 1 & .046 \\
\cline { 2 - 4 } & Sig. (2-tailed) & & .887 \\
\cline { 2 - 4 } & $\mathrm{N}$ & 12 & 12 \\
\hline \multirow{2}{*}{ Y-DJ } & Pearson Correlation & .046 & 1 \\
\cline { 2 - 4 } & Sig. (2-tailed) & .887 & \\
\cline { 2 - 4 } & $\mathrm{N}$ & 12 & 12 \\
\hline
\end{tabular}

\section{Conclusions}

In conclusion, we state that the econometrical models are more elaborate in terms of calculation, while the working and processing with the SPSS program is faster and provides data about the correlations of the variables taken in the study. Also, the coefficient of correlation is a term of the function of trend and an element of determining the total risk of the portfolio

By this study, we can say that the investors are interested in the profitable companies which can remunerate by dividends the capital investments on the financial markets. Thus, the international conjuncture influences such as: sovereign debts, unemployment rate, area army conflicts, agreements with the International Monetary Fund, although influences at a certain moment the prices on the international markets, are not permanent factors for investors on the capital markets.

Regarding the correlation between the variation of the Down Jones indicator and the price of shares in this study, this is weak, although its level is a source of information for the international investors on the Bucharest Stock Exchange, which in the last years decreased more and more.

\section{References}

1. Anghelache G., 2009. Piata de capital in context European, Editura Economica, Bucureşti.

2. Breaz N., 2009. Introducere în econometrie: note de curs si seminar, 1 Decembrie 1918 University Press, Alba Iulia.

3. Chirica L., 2010. Piete financiare si decontari internationale, Editura Economica, Bucureşti.

4. Constantinescu M., 2009. Evolutii recente şi perspective pe piețele bursiere internaționale, Editura Universitaria, Craiova.

5. Hada T., 2006. Plasamente bursiere în Romania, Editura Risoprint, Cluj-Napoca.

6. Reuters, 2000. Introducere în studiul piețelor de titluri de valoare, Editura Economică, Bucureşti,

7. SPSS Program (Statistical Package for the Social Sciences)

8. site-ul Bursei de Valori Bucuresti, http://www.bvb.ro/Companies/qshares.aspx? $\mathrm{m}=\mathrm{bse} \& \mathrm{t}=0$ accessed at 01.09.2011 